\title{
Atmospheric precursors for intense summer rainfall over the UK
}

Article

Accepted Version

Allan, R., Blenkinsop, S., Fowler, H. J. and Champion, A. J. (2020) Atmospheric precursors for intense summer rainfall over the UK. International Journal of Climatology, 40 (8). pp. 3849-3867. ISSN 0899-8418 doi: https://doi.org/10.1002/joc.6431 Available at https://centaur.reading.ac.uk/88032/

It is advisable to refer to the publisher's version if you intend to cite from the work. See Guidance on citing.

To link to this article DOI: http://dx.doi.org/10.1002/joc.6431

Publisher: Wiley

All outputs in CentAUR are protected by Intellectual Property Rights law, including copyright law. Copyright and IPR is retained by the creators or other copyright holders. Terms and conditions for use of this material are defined in the End User Agreement.

\section{www.reading.ac.uk/centaur}

\section{CentAUR}

Central Archive at the University of Reading 
Reading's research outputs online 


\title{
Atmospheric precursors for intense summer rainfall over the UK
}

\author{
Short Title: UK summer rainfall precursors \\ Richard P. Allan * \\ National Centre for Earth Observation \\ Department of Meteorology, University of Reading, UK \\ Stephen Blenkinsop, Hayley J. Fowler \\ School of Engineering, Newcastle University, UK \\ ADRIAN J. CHAMPION \\ College of Engineering, Mathematical and Physical Sciences, \\ UNIVERSITY OF EXETER, UK
}

\footnotetext{
${ }^{*}$ Corresponding author address: Richard Allan, Department of Meteorology, Whiteknights, University of Reading, Reading, Berkshire, UK

E-mail: r.p.allan@reading.ac.uk; Tel: +44 1183787762
} 


\begin{abstract}
Intense sub-daily summer rainfall is linked to flooding impacts in the UK. Characterizing the atmospheric conditions prior to the rainfall event can improve understanding of the large-scale mechanisms involved. The most intense sub-daily rainfall intensity data generated from rain gauge records across the UK over the period 1979-2014 are combined with fields from the ERA Interim reanalysis to characterize atmospheric conditions prior to heavy rainfall events. The 200 most intense 3-hourly events for six UK regions are associated with negative anomalies in sea level pressure $(<-2 h P a)$ and $200 h P a$ geopotential height $(<-60 m)$ to the west or south west of the UK 1 day earlier, with above average moisture, evaporation and dewpoint temperature over north west Europe. Atmospheric precursors are more intense but less coherent between regions for composites formed of the 25 heaviest rainfall events but all display substantial moisture transport from the south or south east prior to their occurrence. Composites for the heaviest events are characterised by a tripole geopotential anomaly pattern across the north Atlantic. Above average geopotential height and dewpoint temperature over Newfoundland and below average geopotential height but elevated evaporation in the north Atlantic are found to be weakly associated with an increased chance of the most intense sub-daily rainfall events 5 to 9 days later.
\end{abstract}

Keywords: Hydrological Cycle; Europe; Water vapour; Extreme Precipitation; Observations; Reanalyses 


\section{Introduction}

Flash flooding from intense rainfall can lead to loss of life and severe damage to infrastructure and the environment (Hapuarachchi et al. 2011; Flack et al. 2019). There is not a simple link between precipitation and flooding (Wasko and Sharma 2017; Stephens et al. 2015). However, flood events are often caused by sustained, heavy precipitation culminating in river flooding as well as intense sub-daily rainfall which can lead to flash flooding in urban environments and small river catchments (Smith and Ward 1998). The intensity of rainfall is expected to increase as atmospheric moisture, and its transport into storms, amplifies with a warming climate (Pfahl et al. 2017; Allan et al. 2014; Fischer and Knutti 2016). Although intensity increases close to those expected for low level water vapour $(\sim 7 \% / K)$ are physically reasonable, the exact magnitude of change is uncertain, depending upon time-scale and spatial extent as well as less well understood dynamical and microphysical factors (Pendergrass 2018; O'Gorman 2015; Nie et al. 2018; Guerreiro et al. 2018; Ali et al. 2018; Bao et al. 2017; Pendergrass et al. 2016; Blenkinsop et al. 2015; Lenderink and Fowler 2017).

In mid-latitude regions, flooding events have been linked with atmospheric rivers (Dettinger et al. 2011; Lavers et al. 2011; Gimeno et al. 2014; Lavers et al. 2016): linear synoptic features of exceptional water vapour transport within mid-latitude cyclones (Dacre et al. 2014, 2019). Although this link appears robust for the winter half year, atmospheric precursors to extreme daily rainfall in the UK are distinct in summer months (Allan et al. 2015) with atmospheric rivers not playing an important role (Champion et al. 2015). The increased importance of smaller-scale systems such as thunderstorms during summer motivates a separate assessment of this season where convection within frontal rain bands and mesoscale convective systems also play a role in surface water flooding and rapid water rise within small river catchments (Lewis and Gray 2010; McGinnigle 2002; Golding et al. 2005; Carlson and Ludlam 1968). Since these processes are operating at smaller scales than can be explicitly represented even by higher spatial resolution numerical simulations (Chan et al. 2016; Kendon et al. 2014), this motivates the assessment of the large-scale atmospheric processes that are important for the generation of intense sub-daily rainfall.

Champion et al. (2019) characterized atmospheric conditions prior to intense sub-daily rainfall in summer over two UK regions estimated from a compilation of quality controlled, hourly rain gauge data (Blenkinsop et al. 2016). Here we investigate in more detail the regional-scale atmospheric precursors to intense sub-daily rainfall, extending to all UK regions and exploiting the latest, updated quality controlled rain gauge data (Blenkinsop et al. 2016; Lewis et al. 2018). Complimenting Champion et al. (2019), here we focus on synoptic precursors in the west Europe region as well as the large-scale north Atlantic, considering additional thermodynamic variables, including evaporation and dew point temperature, which display stronger links with extreme precipitation changes than surface air temperature (Lenderink and van Meijgaard 2010). While Champion et al. (2019) also considered atmospheric stability metrics (e.g. wet bulb potential temperature), which are physically linked with intense thunderstorms and mesoscale convective systems (Lewis and Gray 2010), in the present study we are interested primarily in the larger-scale precursors relating to atmospheric circulation patterns and moisture amount and transport. 

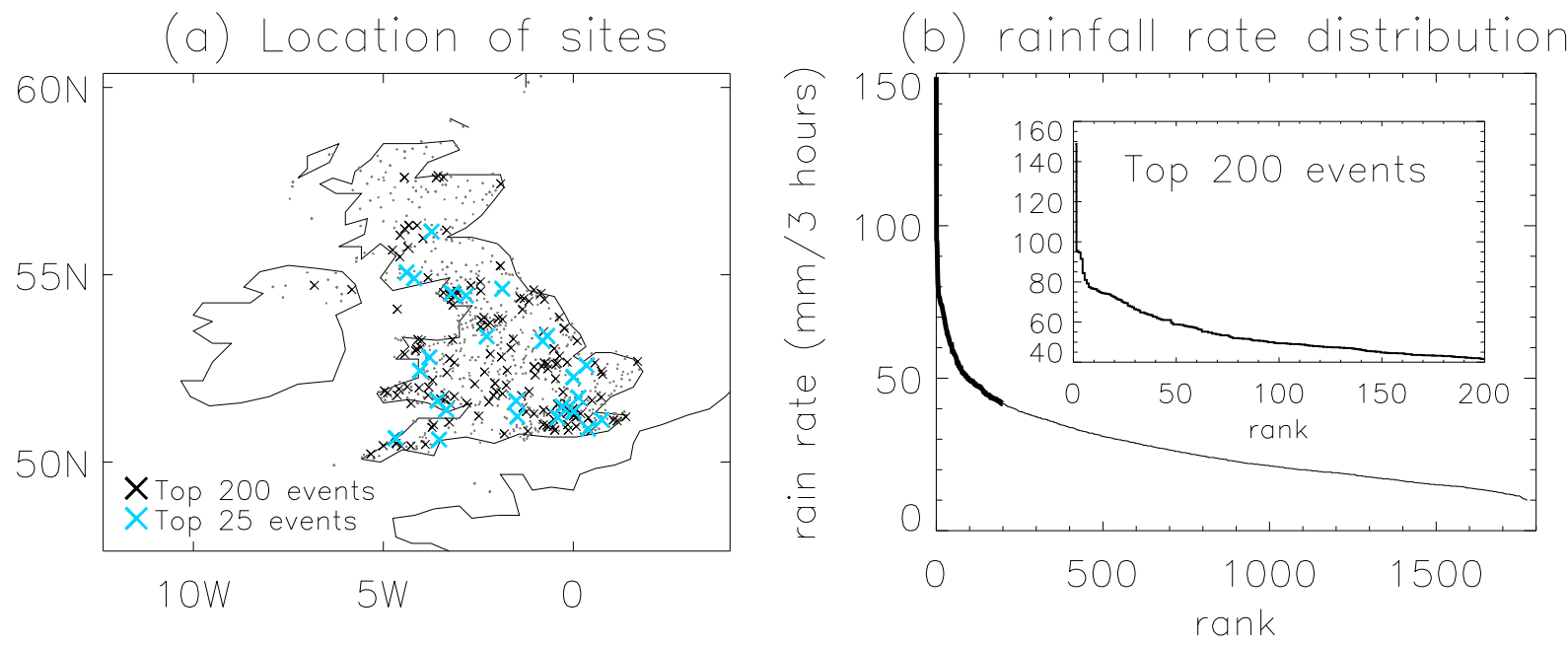

FIG. 1. (a) Geographical location of 3-hour summer rainfall events (left) including location of heaviest $200(\mathrm{x})$ and $25(\mathrm{x})$ rainfall events (other events are marked as dots). (b) The ranked rain rate across all events (the heaviest 200 events in the inset).

\section{Data and Methods}

\section{a. 3-hourly rainfall observations}

A quality-controlled, hourly rainfall dataset was developed by Blenkinsop et al. (2016) using available automated rain gauges across the UK. Here we employ an update to this dataset that implemented additional quality checks on an extended record and removed stations containing inconsistencies with a gridded daily product (Lewis et al. 2018). A peaks-over-threshold (POT) method was applied to extract the highest intensity events for gauge locations across the UK, considering events during the summer months (June-August), the time of year in which the most extreme events are concentrated (Darwish et al. 2018; Gray and Marshall 1998). A POT3 sample was used whereby 3 events per complete year of data are extracted for each station. For example, a gauge record comprising 20 years of data would yield the 60 (3 x 20) largest events in the record. This ensures that extreme events occurring in the same year are not missed as could be the case when using annual maxima while limiting to 3 events to avoid biasing estimates to a single station or year. Consistent with Champion et al. (2019), we consider 3-hourly aggregates of rainfall observations which are thought to relate to flash flooding to a greater extent than hourly intensities.

The locations of the gauges are displayed in Fig. 1, highlighting the heaviest 25 and 200 rainfall events across the UK, along with the ranked 3-hour rain rate across all unique events from the POT3 sample (with the top 200 events in the inset). Of the 29929 summer POT3 events, 1773 events are retained when removing duplicate days. This represents about half of the total number of summer days between 1979 and 2014 (3312), confirming that many events are not extreme and motivating analysis of the heaviest events. The heaviest 200 events identified in each of six UK regions are analysed with details of the heaviest 5 events in each region listed in Table 1. The regions split the UK up into six geographical areas, illustrated in Fig. 2 (region names are defined in Table 1). A region-specific perspective is 


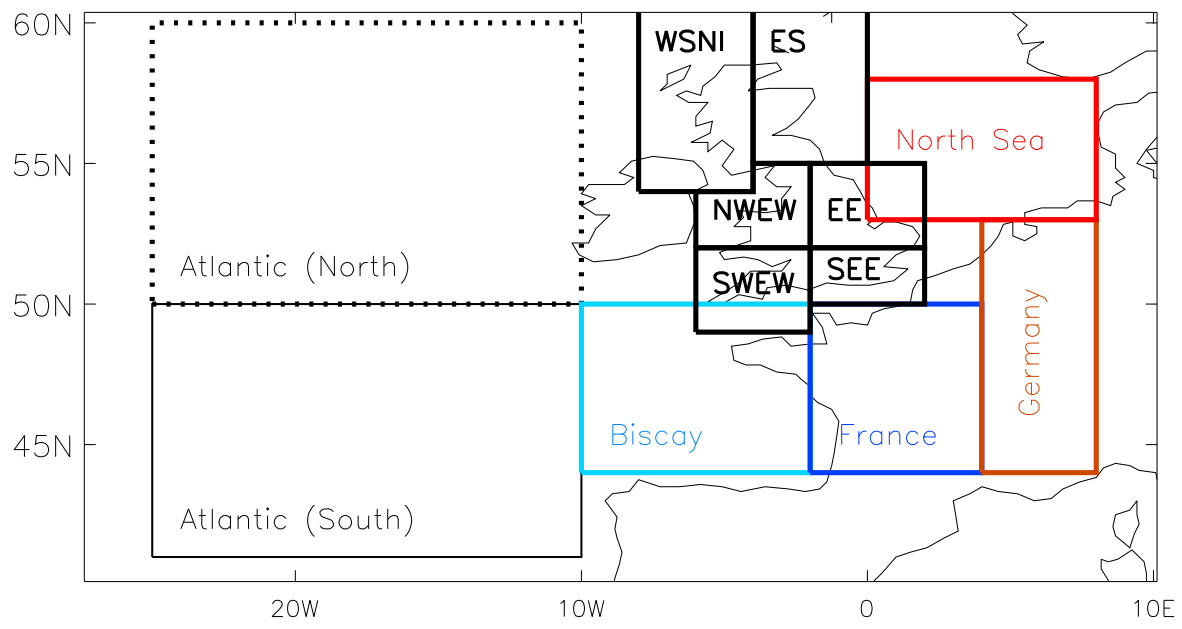

FIG. 2. Location of regions for UK rainfall events detailed in Table 1 and remote regions considered for atmospheric precursor timeseries analysis

beneficial since the nature of extremes depends upon location and geography. Although a more objective approach to selecting regions would account more fully for extreme rainfall behaviour (Jones et al. 2013), the objective here is to seek atmospheric precursors rather than analysing extreme characteristics so the approach adopted is deemed adequate for the purposes of the present study.

\section{b. Additional quality control checks}

The heaviest 3-hour rainfall totals that passed prior quality control checks were first cross-referenced with Met Office daily weather summaries ${ }^{1}$ and manually checked against nearby gauges. Spurious events can occasionally be recorded when gauges become blocked and then subsequently discharge the accumulated water. This was assessed for the heaviest events by comparing rainfall totals with accumulations over multiple days at nearby sites. For example, events recorded at Boreland (ES 20/8/2009, 61.5mm) and Llanfyrnach (SWEW 11/8/2008, 89.6mm) were identified as accumulations and removed. Sustained spurious behaviour compared with nearby sites was also identified at Portmoak (August 2007) and Meadowfoot/Wanlockhead (4/8/2000, $82 \mathrm{~mm})$, both in the ES region, motivated their removal.

There is a fine balance between screening out unreliable totals and removing genuine but highly localized events that do not appear in nearby gauges. Further work is still required to develop an optimal, objective methodology that uses minimal manual intervention to retain a robust record of intense sub-daily rainfall. Nevertheless, the pragmatic approach employed here proved useful in identifying suspect events in an earlier version of the dataset which were independently identified and removed from the updated version of the quality controlled rainfall dataset used in the present analysis. For example, events recorded at two low altitude south east England sites $(104.8 \mathrm{~mm}$ on the 15 th August at Radlett and $100 \mathrm{~mm}$ at Mogden/Isleworth in west London on the 23rd July 2012) and the Higher Hill upland

\footnotetext{
${ }^{1}$ Met Office Daily Weather Reports: https://digital.nmla.metoffice.gov.uk/
} 
TABLE 1. Ranked heaviest 3-hourly rainfall events (ending on the hour indicated) for summer months (June-August) across six UK regions 1979-2014 (see Fig. 2: west Scotland and Northern Ireland (including Isle of Man), WSNI; east Scotland, ES; northwest England and Wales, NWEW; eastern England, EE; southwest England and Wales, SWEW; southeast England, SEE).

\begin{tabular}{|c|c|c|c|c|c|c|c|}
\hline $\begin{array}{r}\text { Region } \\
\text { /rank }\end{array}$ & Location & Lat & Lon & $\begin{array}{r}\text { Altitude } \\
(m)\end{array}$ & Date & $\mathrm{hr}$ & $\begin{array}{l}\text { Rain } \\
(\mathrm{mm})\end{array}$ \\
\hline WSNI/1 & Upper Black Laggan & 55.06 & -4.39 & 411 & $1989 / 8 / 20$ & 19 & 91.5 \\
\hline $\mathrm{WSNI} / 2$ & Low Creoch & 54.90 & -4.19 & 17 & $2010 / 6 / 6$ & 16 & 75.6 \\
\hline $\mathrm{WSNI} / 3$ & Dingwall & 57.60 & -4.45 & 10 & $2004 / 6 / 29$ & 13 & 66.2 \\
\hline $\mathrm{WSNI} / 4$ & Dingwall & 57.60 & -4.45 & 10 & $1988 / 8 / 12$ & 19 & 54.8 \\
\hline $\mathrm{WSNI} / 5$ & Ronaldsway & 54.08 & -4.63 & 17 & $1985 / 7 / 26$ & 20 & 53.4 \\
\hline $\mathrm{ES} / 1$ & Tillicoultry & 56.15 & -3.73 & 30 & $2004 / 7 / 26$ & 07 & 76.8 \\
\hline $\mathrm{ES} / 2$ & Whitley Bay & 55.05 & -1.45 & 15 & $2012 / 6 / 28$ & 18 & 58.6 \\
\hline $\mathrm{ES} / 3$ & Hatton & 57.43 & -1.91 & 40 & $2010 / 8 / 23$ & 18 & 56.4 \\
\hline $\mathrm{ES} / 4$ & Kinloss & 57.65 & -3.56 & 6 & $1982 / 7 / 11$ & 03 & 50.3 \\
\hline $\mathrm{ES} / 5$ & Monaughty/Black Burn & 57.61 & -3.42 & 55 & $2008 / 8 / 25$ & 11 & 49.2 \\
\hline NWEW/1 & Rhydymain/Cae'r-defaid & 52.80 & -3.79 & 361 & $2001 / 7 / 3$ & 18 & 148.8 \\
\hline NWEW/2 & Honister & 54.51 & -3.20 & 360 & $2005 / 8 / 24$ & 06 & 84.4 \\
\hline NWEW/3 & Kentmere & 54.44 & -2.83 & 261 & $2006 / 7 / 5$ & 20 & 81.0 \\
\hline NWEW/4 & Bow Street & 52.44 & -4.03 & 16 & $2006 / 7 / 18$ & 10 & 75.0 \\
\hline NWEW/5 & Ringway & 53.36 & -2.28 & 70 & $1981 / 8 / 6$ & 03 & 73.0 \\
\hline $\mathrm{EE} / 1$ & Uttons Drove & 52.27 & 0.00 & 15 & $2014 / 8 / 8$ & 17 & 94.7 \\
\hline $\mathrm{EE} / 2$ & High Marn & 53.23 & -0.81 & 19 & $2004 / 8 / 9$ & 20 & 77.4 \\
\hline $\mathrm{EE} / 3$ & Copley & 54.62 & -1.87 & 257 & $2009 / 7 / 1$ & 17 & 76.6 \\
\hline $\mathrm{EE} / 4$ & Upton/Sturgate Airfield & 53.37 & -0.68 & 13 & $1982 / 6 / 22$ & 21 & 74.0 \\
\hline $\mathrm{EE} / 5$ & Denver Sluice & 52.58 & 0.35 & 0 & $2005 / 7 / 28$ & 15 & 71.0 \\
\hline SWEW/1 & Ashcombe & 50.60 & -3.53 & 102 & $2012 / 8 / 5$ & 13 & 74.5 \\
\hline SWEW $/ 2$ & Rhoose/Cardiff Airport & 51.40 & -3.34 & 65 & $1995 / 8 / 2$ & 17 & 74.3 \\
\hline SWEW $/ 3$ & Slaughterbridge & 50.64 & -4.67 & 212 & $2004 / 8 / 16$ & 15 & 72.5 \\
\hline SWEW $/ 4$ & Mynydd Werfa & 51.64 & -3.57 & 567 & $1987 / 8 / 24$ & 10 & 71.3 \\
\hline SWEW $/ 5$ & Bodrane & 50.43 & -4.53 & 128 & 2004/8/11 & 23 & 67.4 \\
\hline $\mathrm{SEE} / 1$ & Andover & 51.22 & -1.47 & 63 & $2009 / 8 / 6$ & 11 & 95.4 \\
\hline $\mathrm{SEE} / 2$ & Thornwood & 51.72 & 0.14 & 76 & $1993 / 6 / 10$ & 20 & 79.2 \\
\hline $\mathrm{SEE} / 3$ & Bethersden & 51.13 & 0.75 & 35 & $1994 / 6 / 27$ & 11 & 76.4 \\
\hline $\mathrm{SEE} / 4$ & Holmbury & 51.19 & -0.41 & 155 & $2008 / 7 / 15$ & 01 & 74.2 \\
\hline $\mathrm{SEE} / 5$ & Kew Gardens & 51.48 & -0.29 & 5 & $1983 / 7 / 6$ & 16 & 73.7 \\
\hline
\end{tabular}


$(451 \mathrm{~m})$ site (NWEW 28/8/1990, 140mm) were removed by the updated quality control following Lewis et al. (2018) and the additional manual checks. These events were included in the composites of Champion et al. (2019) (their Table 1) Preliminary analysis had also marked these events as suspect based on a lack of corroborating evidence from the Met Office daily weather reports and the Mogden observations during the 17:25 and 17:49 event were marked as unchecked in the raw data. Similarly, events recording above $70 \mathrm{~mm}$ on the 13th and 25th July at Pant Mawr (an upland NWEW station) were also removed by the updated quality control as were many events recording above $100 \mathrm{~mm}$ of rainfall for stations in south Wales including Cowbridge, Nantyrwdd and Sennybridge.

\section{c. ERA Interim reanalysis data}

Atmospheric conditions prior to the 3-hourly rainfall extremes (atmospheric precursors) are extracted from the European Centre for Medium-range Weather Forecasts (ECMWF) Interim reanalysis (ERA Interim), a state of the art reanalysis system covering the period 1979-present (Dee et al. 2011). A fixed configuration of the ECMWF atmospheric model is observationally constrained using 4-dimensional data assimilation. We considered $0.75 \times 0.75$ degree latitude/longitude resolution 6-hourly data, extracting dewpoint temperature $(T d)$, pressure at mean sea level $(P M S L)$, surface evaporation $(E)$, geopotential height at 200 $h P a(Z 200)$, column-integrated water vapour $(C W V)$ and column integrated horizontal water vapour transport $(I V T)$ calculated from the eastward and northward components as:

$$
I V T=\sqrt{\left(\frac{1}{g} \int_{p_{s}}^{0} q u \mathrm{~d} p\right)^{2}+\left(\frac{1}{g} \int_{p_{s}}^{0} q v \mathrm{~d} p\right)^{2}},
$$

where $g$ is acceleration due to gravity, $p$ is atmospheric pressure, $p_{s}$ is surface pressure, $q$ is specific humidity, $u$ is eastward wind and $v$ is northward wind. $C W V$ and IVT are useful measures of total atmospheric water vapour and its horizontal transport that have previously been linked with heavy rainfall events (Lavers et al. 2011; Gimeno et al. 2014).

\section{d. Evaluation of heaviest rainfall events}

Following the additional quality control checks, each extreme 3-hour duration summer rainfall event was matched with the daily mean atmospheric conditions using the variables extracted from ERA Interim on the days leading up to the event. Anomalies were subsequently computed by subtracting the pentad climatology centred on the calendar day and these are formed into composites across 25 or 200 of the most intense rainfall events up to 9 days prior to each event. The region $30^{\circ} \mathrm{W}-10^{\circ} \mathrm{E}, 40-60^{\circ} \mathrm{N}$ is assessed in detail with a wider North Atlantic region also considered.

Where multiple events occur in a single day the heaviest event is retained (Section 2a) for each of the regions considered (WSNI, ES, NWEW, EE, SWEW, SEE; defined in Table 1): For all POT3 events, 37\% of WSNI events are retained while for the remaining regions between 10\% (SEE, EE) and 23\% (ES) of daily events are retained. This makes sense as in the more sparsely gauged and geographically complex WSNI and ES regions, each rainfall event or associated events affect fewer separate sites. In other regions, synoptic events leading to heavy rainfall are often large-scale in nature and affect multiple gauging sites, 

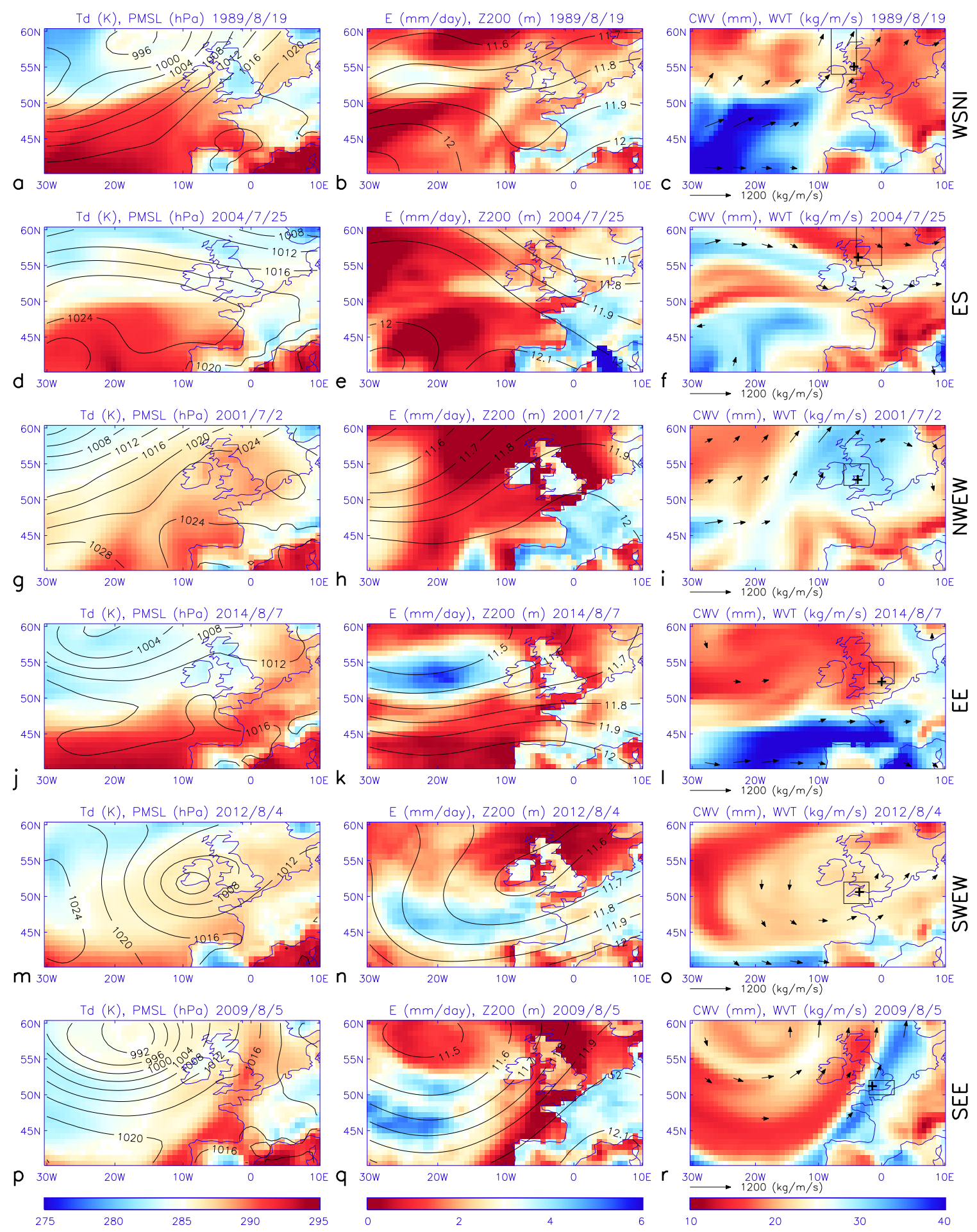

FIG. 3. Atmospheric conditions on the day before the single heaviest recorded 3-hourly summer rainfall event in each of six UK regions (denoted by boxes in right column with gauge location marked as +$)$. Left column: dewpoint temperature $(T d$, colours) and pressure at mean sea level ( $P M S L$, contours). Middle column: evaporation (E, colours) and geopotential height at $200 \mathrm{hPa}$ (Z200, contours). Right column: column integrated water vapour $(C W V$, colours) with arrows denoting water vapour transport magnitude and direction $(W V T)$. Colour bars are chosen such that red denotes warm/dry and blue cool/wet. 
particularly where in close proximity. Removing events occurring on the same day ensures that atmospheric precursors associated with events affecting multiple gauges in a single day are not given extra weight when composites are computed over multiple events (i.e. the events are independent).

To illustrate the method, Fig. 3 displays atmospheric conditions the day before the heaviest event in each region (which are geographically depicted by boxes in the right column). Since the recorded intensity occurs at different times of day, the lead time will differ somewhat but keeping to calendar day is preferred for simplicity. Of the most intense events listed in Table 1, the NWEW region contains the heaviest 3-hour rainfall total $(148 \mathrm{~mm})$. The heaviest 3 events for this region were all recorded for altitudes of at least $260 \mathrm{~m}$. Although altitude clearly plays a role in determining rainfall intensity of some sites, there is a range of station altitudes for the top 5 events across regions. Contrasting intensities across the regions motivates a regional analysis of atmospheric precursors.

There is a diverse range of synoptic precursors to the heaviest 3-hourly events recorded in each region (Fig. 3). Most events are associated with cyclonic flows and low geopotential to the north or north west of the UK, the exception being for the Tillicoultry event (Fig. 3d-f). There is not a consistent signal for dewpoint temperature or evaporation although there are some indications of high evaporation rates over continental Europe. Although atmospheric river patterns were not found to be a driver of extreme daily rainfall in summer (Champion et al. 2015), linear moisture transport features are present for some of the heaviest 3-hourly rainfall events, for example in the NWEW region (Honister, Bow Street and Ringway) and the WSNI region including the Black Laggan and both Dingwall events (not shown).

Most of the heaviest events that were scrutinized are clearly identified in the Met Office daily summaries ${ }^{1}$. The Black Laggan event (Fig. 3a-c) matches reports of thunderstorms in southern Scotland associated with an advancing cold front. The 5th heaviest WSNI event at Ronaldsway also matches a reported thunderstorm associated with high dewpoint temperature and a cyclonic southeasterly flow that led to $47 \mathrm{~mm}$ of rainfall in 2 hours. The heaviest rainfall event observed (Rhydymain; Fig. 3g-i) coincides with reports of heavy and thundery showers with localised downpours over western Britain associated with a convergence line ahead of a cold front; this also generated an area of thundery showers that moved north over northern Wales during the evening, probably associated with a mesoscale convective system as part of a "modified" Spanish Plume synoptic pattern (Lewis and Gray 2010). Other events in the NWEW region appear consistent with reports of heavy rain in the daily weather summaries and the Ringway event on the 6th August 1981 coincides with mesoscale convective systems (Gray and Marshall 1998). The Uttons Drove EE event (Fig. 3j-l) is clearly associated with some very heavy, thundery downpours that developed over central England associated with a developing low pressure moving from the south.

For the SWEW region, torrential downpours on the 5th August 2012, associated with with slow moving showers that resulted in localized flooding ${ }^{2}$, match the SWEW Ashcombe event and the Rhoose/Cardiff Airport event is corroborated by reports of thunderstorms widely affecting southern Britain (Institute of Hydrology 1996). The Slaughterbridge event is associated with the same intense convergence line that generated the Boscastle flood of 2004. For SEE, the Andover event on the 6th August 2009 (Fig. 3p-r) is corroborated by reports

\footnotetext{
${ }^{2}$ https://www.ofcom.org.uk/__data/assets/pdf_file/0025/74356/mo_ofcom_report.pdf
} 
of a line of heavy and thundery showers extending from the Isle of Wight to Lincolnshire associated with a static cold front and rainfall rates exceeding $10 \mathrm{~mm} /$ hour were recorded at Heathrow ${ }^{1}$. The Thornwood event also matches reports of flooding in the national media and evidence of mesoscale convective systems (Gray and Marshall 1998). Thunderstorms reported in the Met Office daily summaries corroborate the Kew event on the 6th July 1983, yet totals at nearby Heathrow were only $18 \mathrm{~mm}$ over the same 3-hour period, indicative of the localised nature of thunderstorms, though inaccuracies in the extreme totals cannot be ruled out.

Some cases, while appearing plausible in relation to the synoptic patterns and often associated with weather fronts, could not be clearly identified as a heavy rainfall event. Although quality control removed many of the heaviest ES events, of the remaining records, the Tillicoultry event (Fig. 3d-f) remains suspect despite no clear signs of spurious gauge behaviour as does the Kinloss ES observation (11th July 1982) that could only be matched with a mesoscale convective system that was far to the south (Gray and Marshall 1998).

The lack of confirmation of some events in independent records highlights the continuing importance of consistency checking across datasets and further questions the timing, magnitudes or existence of some of the events despite careful quality control Blenkinsop et al. (2016); Lewis et al. (2018). This also motivates the use of composites of atmospheric precursors across a number of heavy rainfall events.

\section{Composites of atmospheric precursors to sub-daily rainfall extremes}

\section{a. Atmospheric precursors 1-day prior to intense rainfall events}

Daily-mean synoptic conditions 1-day prior to the day of the heaviest 25 or 200 3-hourly rainfall events within each of the 6 regions were extracted from the ERA Interim reanalysis. Anomalies were computed relative to the pentad-mean climatology centred on each date and composites formed for each variable considered (Fig. 4-5). Stippling denotes where anomalies in $T d, E$ and $C W V$ are significantly different from zero at the $90 \%$ confidence level based upon a two-tailed t-test (e.g. Lavers et al. 2015), assuming $n-1$ degrees of freedom, where $n$ is the number of events in the composite.

One day prior to the heaviest 200 events in each region, negative pressure anomalies (around -2 to $-4 \mathrm{hPa}$ ) and geopotential anomalies (around -60 to $-100 \mathrm{~m}$ ) are present to the west or south west of the UK (Fig. 4). This is consistent with an anomalous cyclonic southerly airflow and associated moisture transport from the south affecting the UK, with elevated dewpoint temperature and moisture across north west Europe and elevated evaporation in continental north west Europe but also to the west of the UK over the Atlantic associated with cool, relatively dry northerly winds. Anomalously low ocean evaporation to the south east of France $\left(4^{\circ} \mathrm{E}, 43^{\circ} \mathrm{N}\right)$, apparent for all event composites, is presumably explained by occasionally very high evaporation rates associated with the hot, dry summer form of the Mistral wind that is inhibited during the southerly flows associated with intense summer rainfall in the UK. Interestingly, the suspect Tillicoultry event displays an opposite sign of evaporation anomaly in this region (Fig. 3e) relating to a northerly airflow associated with a Mediterranean cyclone to the east. 

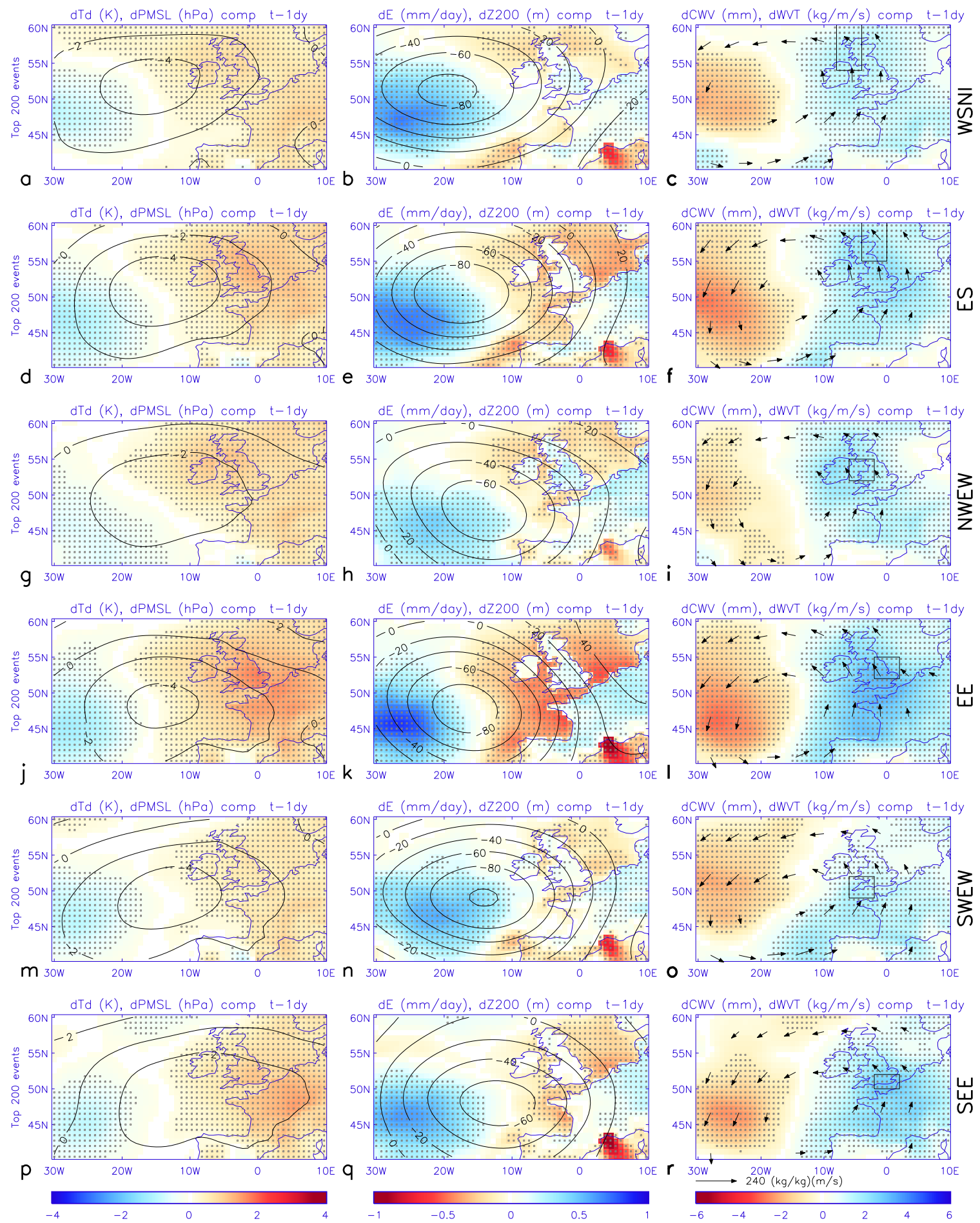

Fig. 4. Atmospheric precursor composites of anomalies 1-day prior to the 200 heaviest regional 3-hourly summer rainfall events for the WSNI (a-c), ES (d-f), NWEW (g-i), EE $(\mathrm{j}-\mathrm{l})$, SWEW (m-o) and SEE (p-r) regions defined in Table 1. Left column: dewpoint temperature $(T d$, colours) and pressure at mean sea level (PMSL, contours). Middle column: evaporation ( $E$, colours) and geopotential height at $200 \mathrm{hPa}$ (Z200, contours). Right column: column integrated water vapour $(C W V$, colours) with arrows denoting water vapour transport $(W V T)$. Stippling denotes where anomalies in $T d, E$ and $C W V$ are significantly different from zero at the $90 \%$ confidence leve1. 

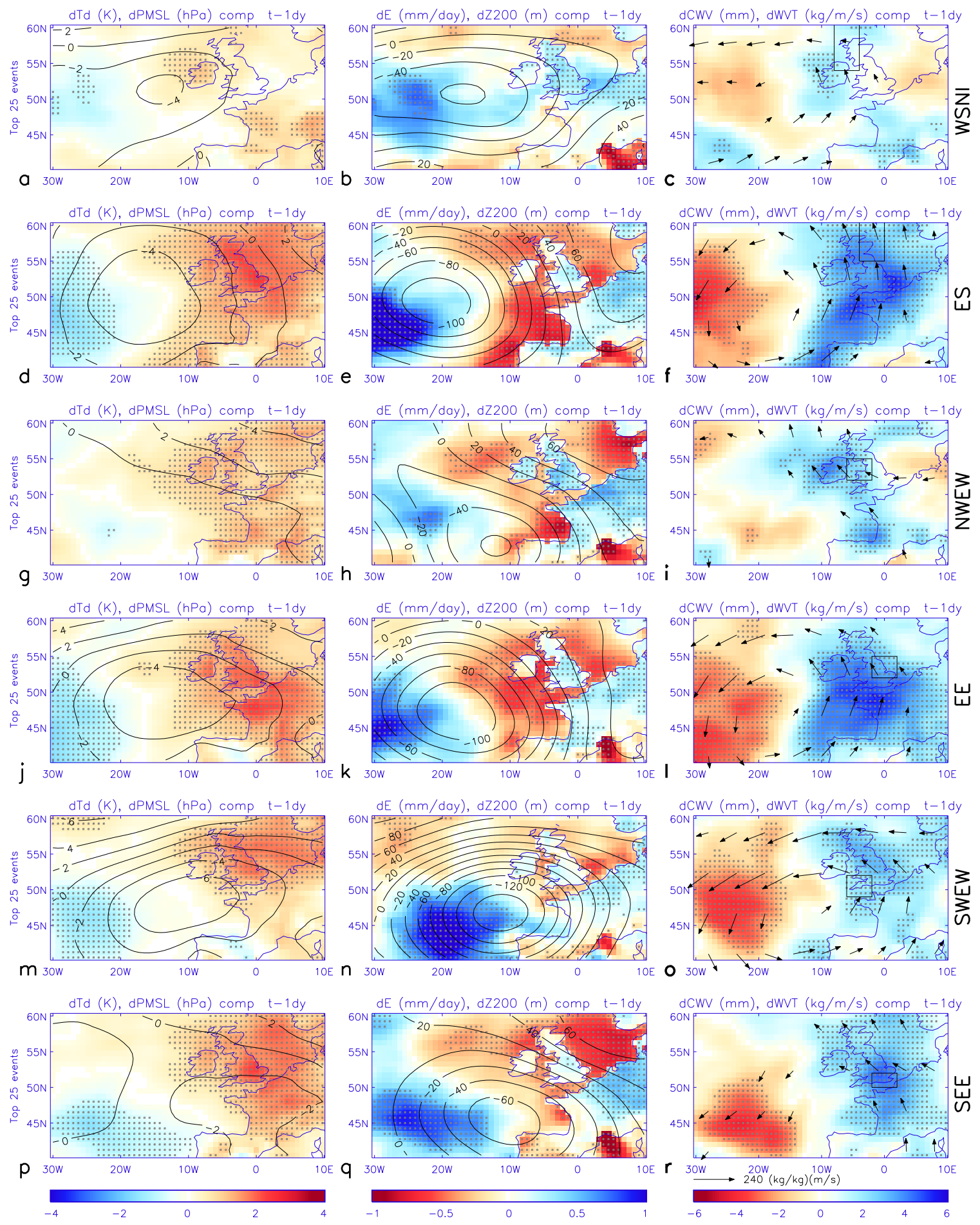

Fig. 5. As Fig. 4 but for composites of the 25 heaviest regional 3-hourly summer rainfall events 

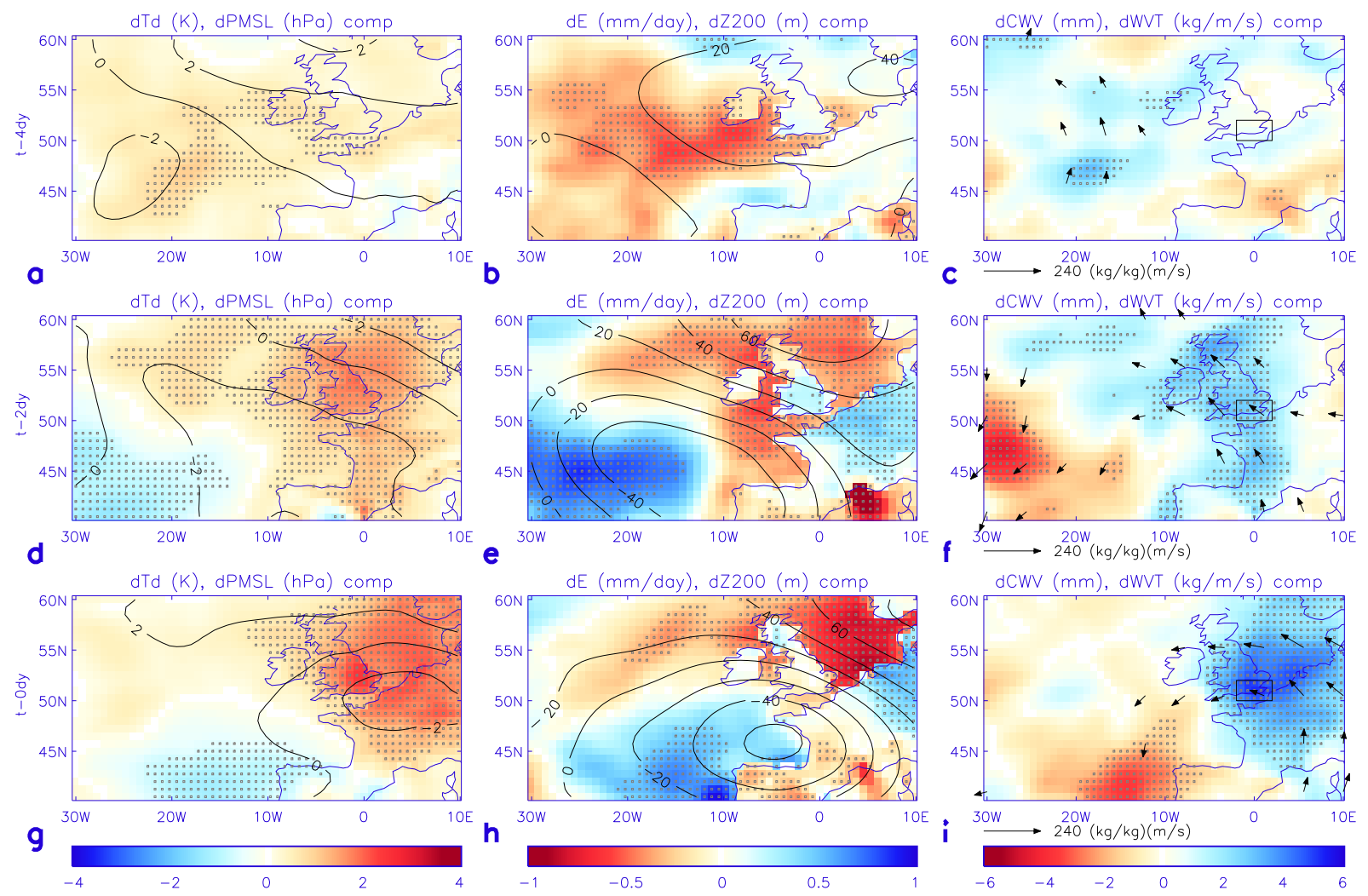

FIG. 6. Atmospheric precursor composites (a-c) 4 days, (d-f) 2 days and (g-i) on the day of the 25 heaviest regional 3-hourly summer rainfall events for South East England (SEE). Left column: dewpoint temperature ( $T d$, colours) and pressure at mean sea level (PMSL, contours). Middle column: evaporation ( $E$, colours) and geopotential height at $200 h P a$ (Z200, contours). Right column: column integrated water vapour ( $C W V$, colours) with arrows denoting water vapour transport $(W V T)$.

Precursor composites for the heaviest 25 events (Fig. 5) display more diversity across regions and generally larger magnitude anomalies in atmospheric fields compared to the 200 event composite (Fig. 4). As with the 200 member composite, the heaviest 25 events are associated with above average evaporation to the west of the UK and over continental Europe with positive $T d$ and $C W V$ anomalies over western Europe and anomalously strong integrated moisture transport from the south west, south and south east. There is similarity in anomaly patterns for the ES, EE and SWEW regions with strong cyclonic southerly flow and negative anomalies in PMSL $(<-2 h P a)$ and $Z 200(<-100 m)$ to the south west of the UK. A contrasting orientation of the geopotential height anomaly field for SEE and NWEW (Fig. 5h,q) is associated with moisture transport from the south east (Fig. 5i,r).

Precursors to intense daily rainfall were previously found to be distinct in summer months compared to other seasons for south east England (Allan et al. 2015). Nevertheless, the importance of higher moisture amount and transport in determining these heavy rainfall events is consistent with previous analysis of daily events and underlines how thermodynamic increases in moisture in a warming climate are anticipated to intensify precipitation extremes 

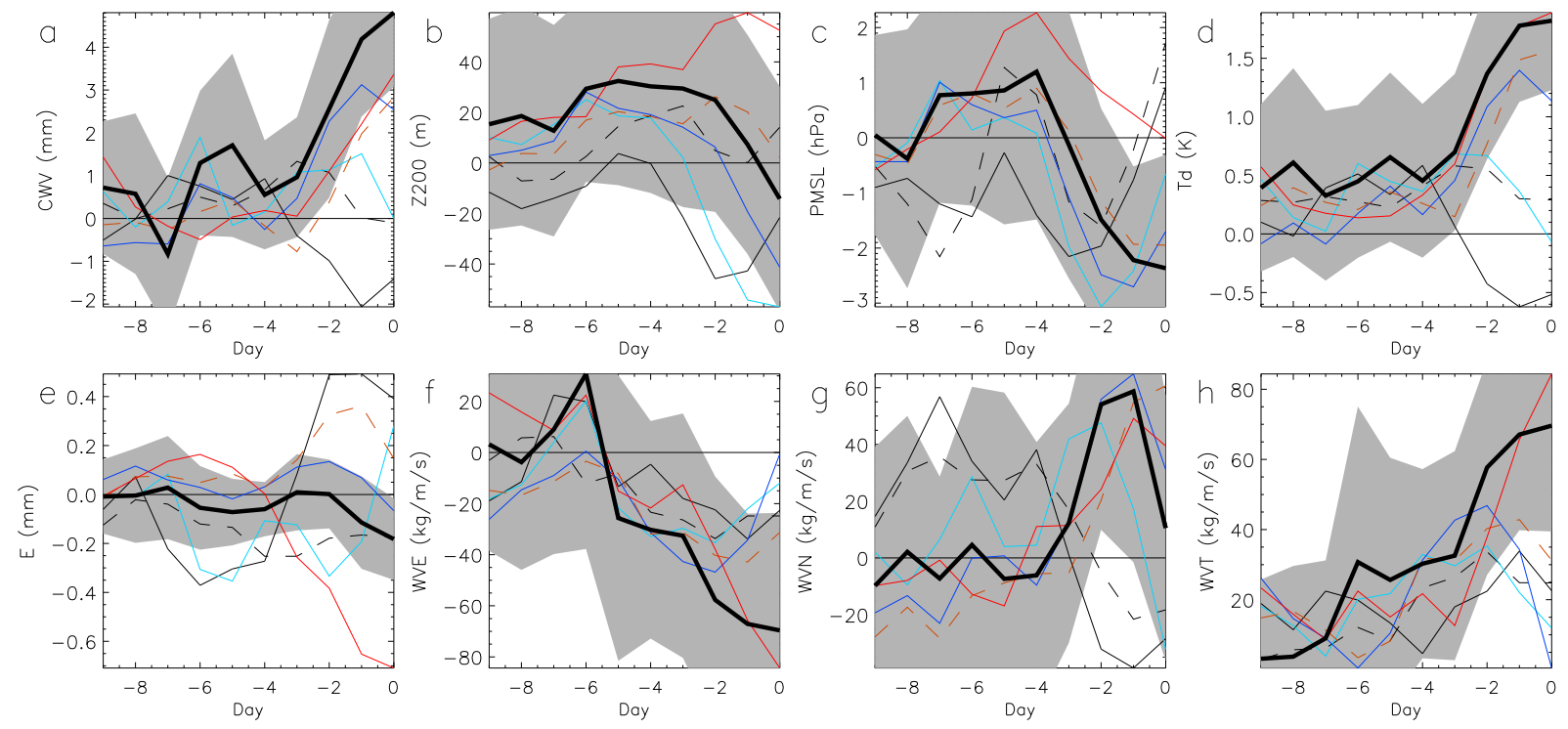

- - Atl_Nth -AtI_Sth

- Biscay

- France

- - Germany _Nth_Sea

-SEE

FIG. 7. Regional anomaly mean composites of atmospheric variables prior to the heaviest 25 3-hourly rainfall events over South East England (SEE) 1980-2014: (a) column integrated water vapour $(\mathrm{mm})$, (b) geopotential height at $200 \mathrm{~m}$, (c) pressure at mean sea level $(h P a)$, (d) dewpoint temperature $(K)$, (e) Evaporation $(\mathrm{mm} /$ day $)$, (f) eastward water vapour transport $(\mathrm{kg} / \mathrm{m} / \mathrm{s})$, (g) northward water vapour transport $(\mathrm{kg} / \mathrm{m} / \mathrm{s})$ and $(\mathrm{h})$ magnitude of water vapour transport $(\mathrm{kg} / \mathrm{m} / \mathrm{s})$. The grey shaded region represents \pm 1 standard deviation across the 25 events making up the composite for the region local to the event.

(Fischer and Knutti 2016; Lenderink and Fowler 2017).

\section{b. Time dependence of precursors to intense rainfall events}

The emergence over time of the large-scale atmospheric precursors to intense summer rainfall is useful in understanding the mechanisms involved and in seeking linkages between large-scale weather patterns many days before the events. Figures 6-11 describe the time dependence of precursors to the heaviest events in the south east England (SEE) and north west England/Wales (NWEW) regions. Positive geopotential height anomalies over the UK are apparent 4-days prior to the south east England events (Fig. 6b) symptomatic of weakly anticyclonic conditions. High evaporation rates over north west Europe and the Atlantic Azores region emerge 2-days before the event (Fig. 6e).

Time series of atmospheric precursors averaged over ocean and land regions surrounding the UK (illustrated in Fig. 2) up to 9 days prior to the rainfall events are also analysed. There are increases in moisture $(\sim 3-4 \mathrm{~mm}$; Fig. 7a) and dewpoint temperature $(\sim 1 K$; Fig. $7 \mathrm{~d})$ from 4-days prior to the events over France, Germany, the North Sea and over the local SEE region. Surface pressure and geopotential height also drop during this period over SEE and France/Biscay (Fig. 7b-c) with elevated evaporation over Germany and the Atlantic south region. Moisture transport increases from 6-days prior to the event in SEE and over the North Sea from 3 days prior, primarily due to an enhanced east to west component 

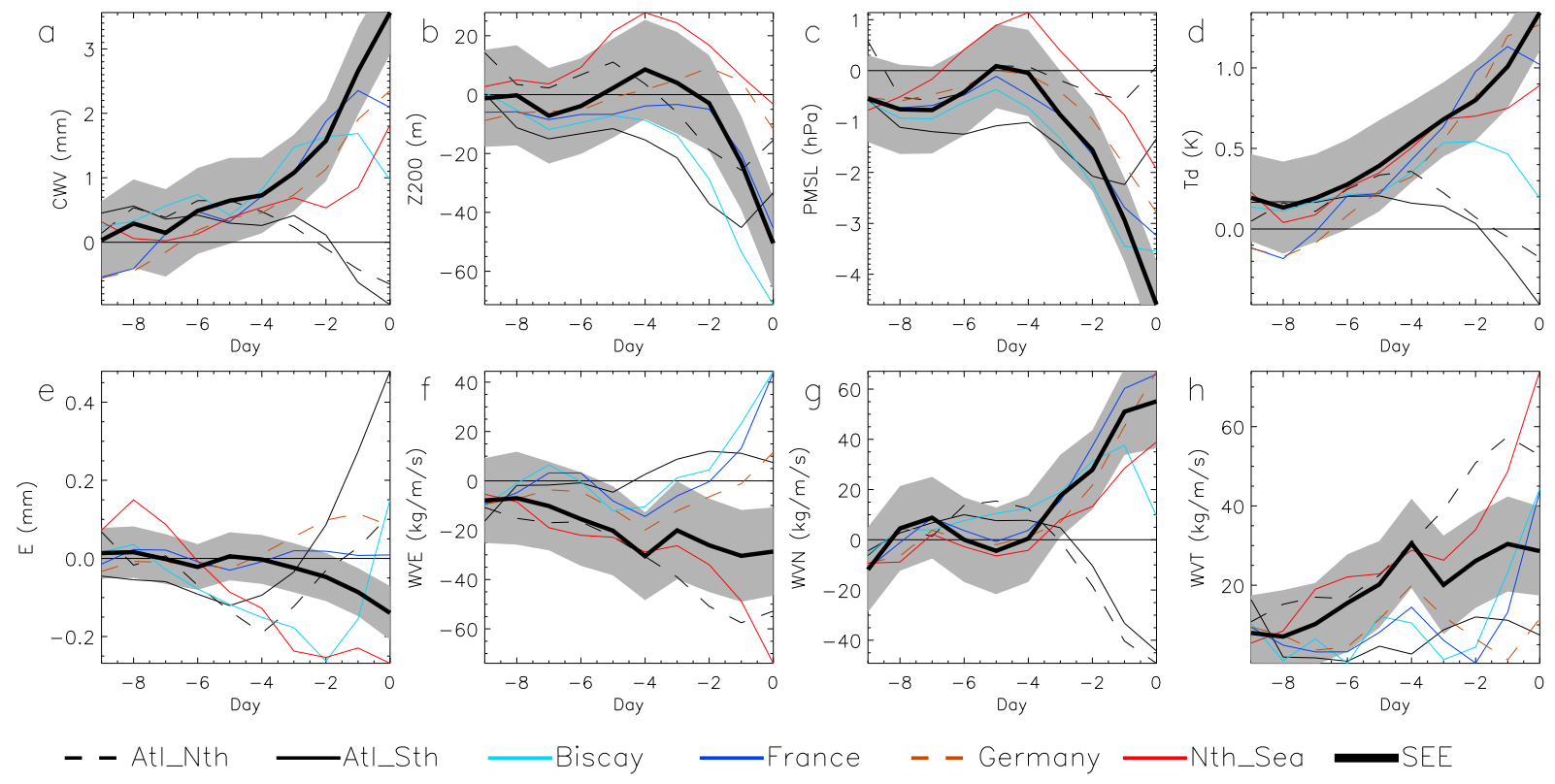

- - Germany — Nth_Sea

SEE

FIG. 8. As Fig. 7 but for time dependence of atmospheric precursors prior to the heaviest 200 SEE events.

(Fig. 7f-h).

For the heaviest 200 events affecting SEE (Fig. 8), moisture and dewpoint temperature increase in the local SEE region by a similar magnitude to the 25-event composite but with increases more gradually from 7 -days prior to the events with less variance across the composite as denoted by the shading (Fig. 8a,d). Decreases in geopotential height $(\sim 4 h P a)$ and sea level pressure $(\sim 40 \mathrm{~m})$ affect the SEE region from 2-3 days prior to the events and also the Biscay region where evaporation increases are also most pronounced . Increases in moisture transport from 8 days prior to the event are most pronounced over the North Sea region $(60 \mathrm{~kg} / \mathrm{m} / \mathrm{s})$ but in contrast to the more extreme 25-member composite this is dominated by enhanced northward vapour transport from 4 days prior that also affects the France/Germany/SEE regions. Positive geopotential height anomalies affect the North Sea for south east and eastern England events (SEE/EE) which are symptomatic of a weak anticylonic influence.

In general water vapour transport increases over most regions considered in the days prior to the 200 composite events (Fig. 8h) while the signal of anomalous southward transport in Atlantic regions to the west of the UK and enhanced northward transport for regions to the south and east of the UK (Fig. 8g) are associated with cyclonic conditions centred to the west of the UK. Negative anomalies in geopotential height $(<-40 \mathrm{~m})$ and high evaporation rates to the west of the UK and positive moisture and dewpoint temperature anomalies over the UK are present in the 200 event composite 4-days prior (Fig. 9), though the dynamical signals are weak for the SEE region. This could reflect contrasting dynamical factors explaining intense sub-daily rainfall events over south eastern England although elevated dewpoint temperature and moisture appear robust. The atmospheric precursors to heavy daily rainfall in south east England during summer were previously found to contrast with other seasons (Allan et al. 2015). 

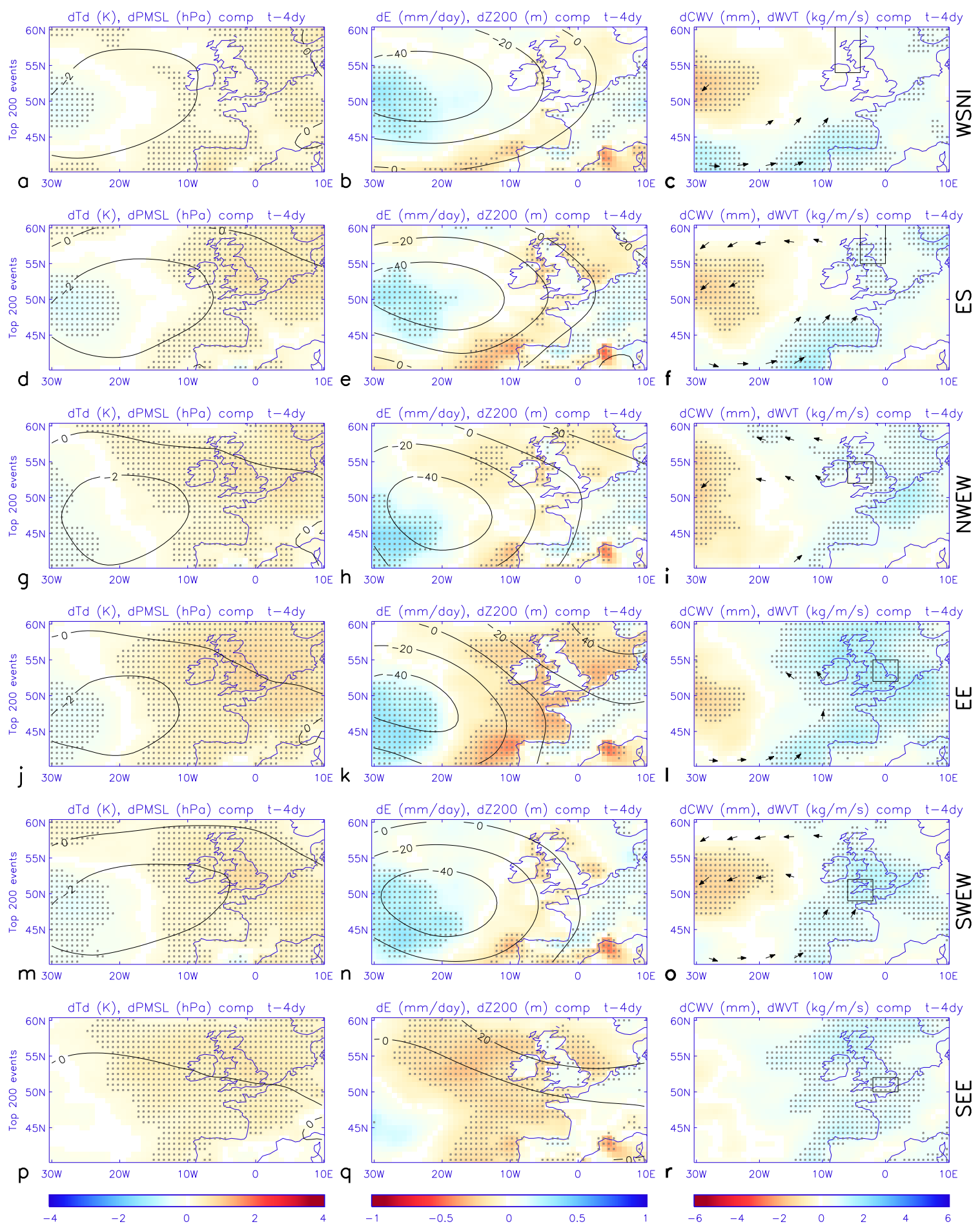

Fig. 9. As Fig. 5 but for atmospheric precursors 4 days prior to heaviest 200 events across all UK regions 

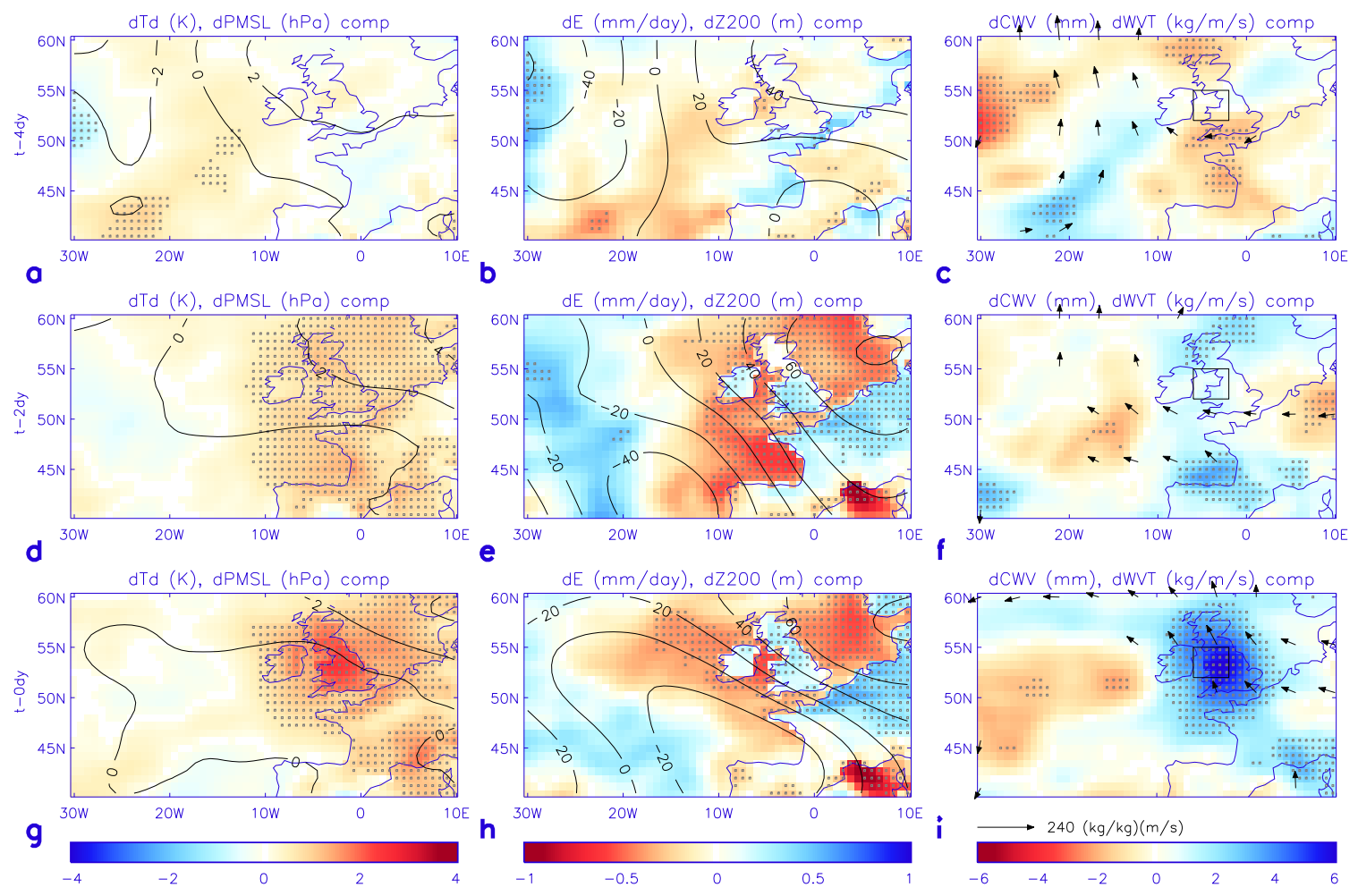

Fig. 10. As Fig. 6 but for NW England and N Wales (NWEW).

Over north western England and Wales (NWEW), the day of the most intense 3-hourly rainfall events are characterized by high dewpoint temperature, moisture and moisture transport from the south east over the UK region with elevated evaporation over much of north western continental Europe (Fig. 10g-i), consistent with analysis of daily rainfall extremes (Allan et al. 2015). This is associated with a dipole of negative sea level pressure and geopotential anomalies to the south west of the UK and positive anomalies to the north east (Fig. 10g-h), which are present but weaker at 2 and 4-days prior to the events and shifted to the west (Fig. 10d-e,a-b). The signal of anomalously strong moisture transport from the south is also shifted to the west of the UK 4 days prior to the events (Fig. 10c) indicating that a slow, eastward propagation of large-scale weather patterns precede the intense rainfall events.

Time series up to 9 days prior to the events for the NWEW region display consistent increases in moisture and its northward transport (Fig. 11). In the 2-days prior to the rainfall events, moisture transport is high in the regions to the south and east of the UK (Biscay/France/Germany; Fig. 11h). Anomalously high geopotential height 4 days prior to rainfall events $(>40 \mathrm{~m})$ are present over the Germany/North Sea/NWEW regions (Fig. 7b), suggesting weakly anticylonic conditions that are also associated with low moisture over the UK (Fig. 10c). Negative geopotential height anomalies over the Atlantic to the west 4 days prior move to the south west of the UK leading up to the event. Given the robust signal in geopotential height anomalies across the north west Europe region affecting all regions 1 to 4-days prior to the events (Fig. 4-10), a larger spatial scale perspective, as also considered by Champion et al. (2019), is therefore deemed necessary to understand the atmospheric 

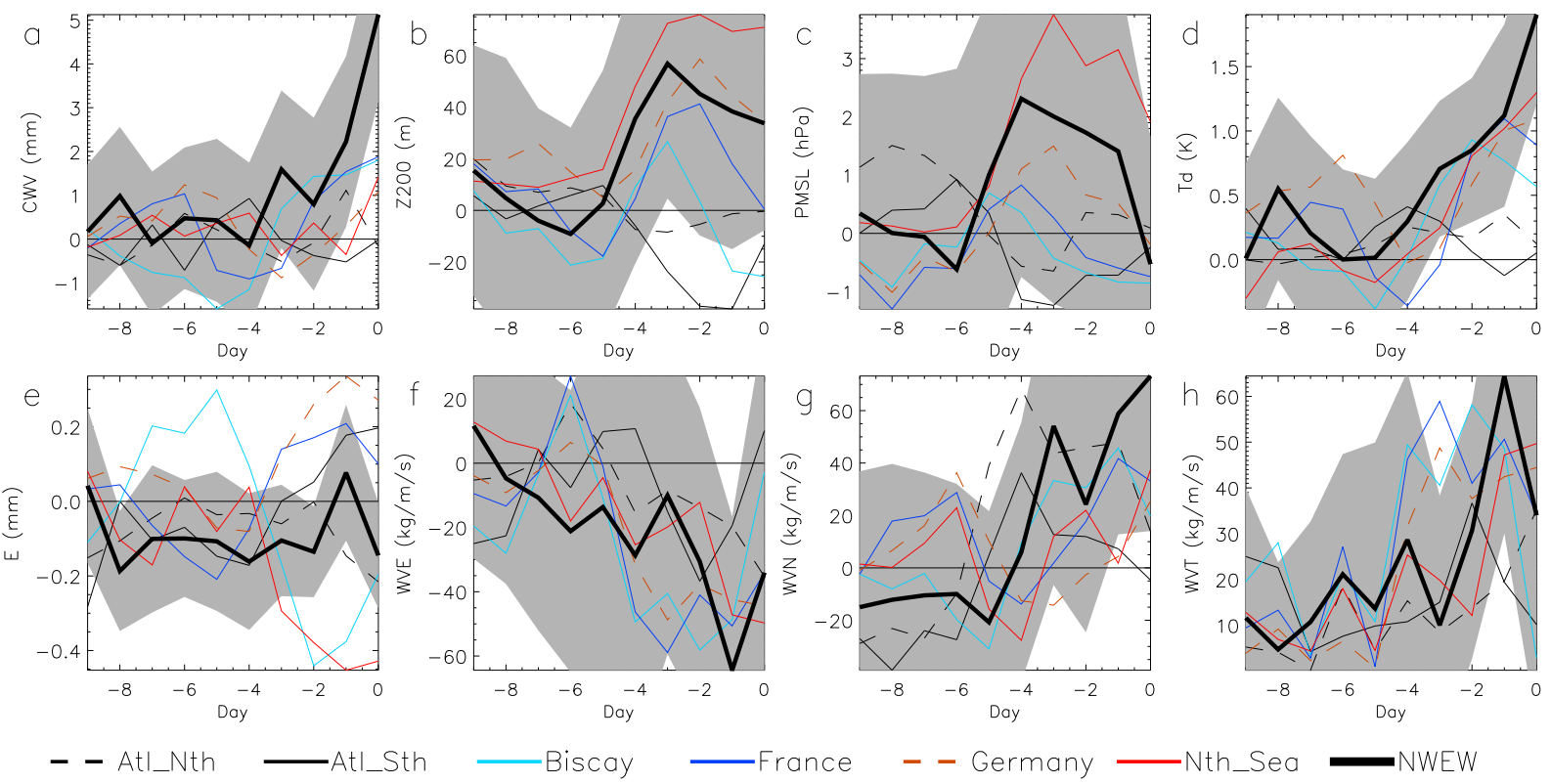

-France

- - Germany

Nth_Sea NWEW

FIG. 11. Regional anomaly mean composites of atmospheric variables prior to the heaviest 25 3-hourly rainfall events, as Fig. 7 but over North West England and North Wales (NWEW)

context for these anomalies.

\section{c. Atmospheric precursors at the north Atlantic scale}

Previous work has found blocking of the jet stream over the north Atlantic to influence thunderstorm activity over Europe (Mohr et al. 2019) through promoting or inhibiting the advection of warm, moist and unstable air masses from the south or southwest. This will depend on the location of the block in relation to the region of suppressed or enhanced activity. We therefore now consider the larger-scale precursors to the summer sub-daily rainfall extremes in $3 \mathrm{UK}$ regions.

Composites of the large-scale atmospheric precursors to the heaviest 25 rainfall events for the WSNI, NWEW and SEE regions were computed across the larger north Atlantic region to assess the more remote influences. Atmospheric fields 5 days prior to the heaviest 3-hour events are displayed in Fig. 12. Consistent with Champion et al. (2019), the geopotential height fields display coherent patterns with some weak signals of high evaporation rates in the north west Atlantic and strong moisture fluxes affecting parts of the north Atlantic, particularly for WSNI precursors. Elevated dewpoints are seen over Newfoundland from 9 days prior to the events with increasing evaporation in the mid north Atlantic from 5 days prior, with both signals propagating toward the east (not shown). The geopotential height fields are characterised by a tri-pole pattern with elevated values over Newfoundland (NFL) and near the UK with depressed values in the central northern Atlantic (CNA) around 40-50 $\mathrm{W}, 50-60^{\circ} \mathrm{N}$ (see boxes in Fig. 12b).

The tripole pattern of geopotential height appears to signify a meandering jet stream that, for the cases identified, promotes a warm, moist flow towards the UK from the south. Francis and Vavrus (2015) use geopotential height contours and the ratio of meridional and 

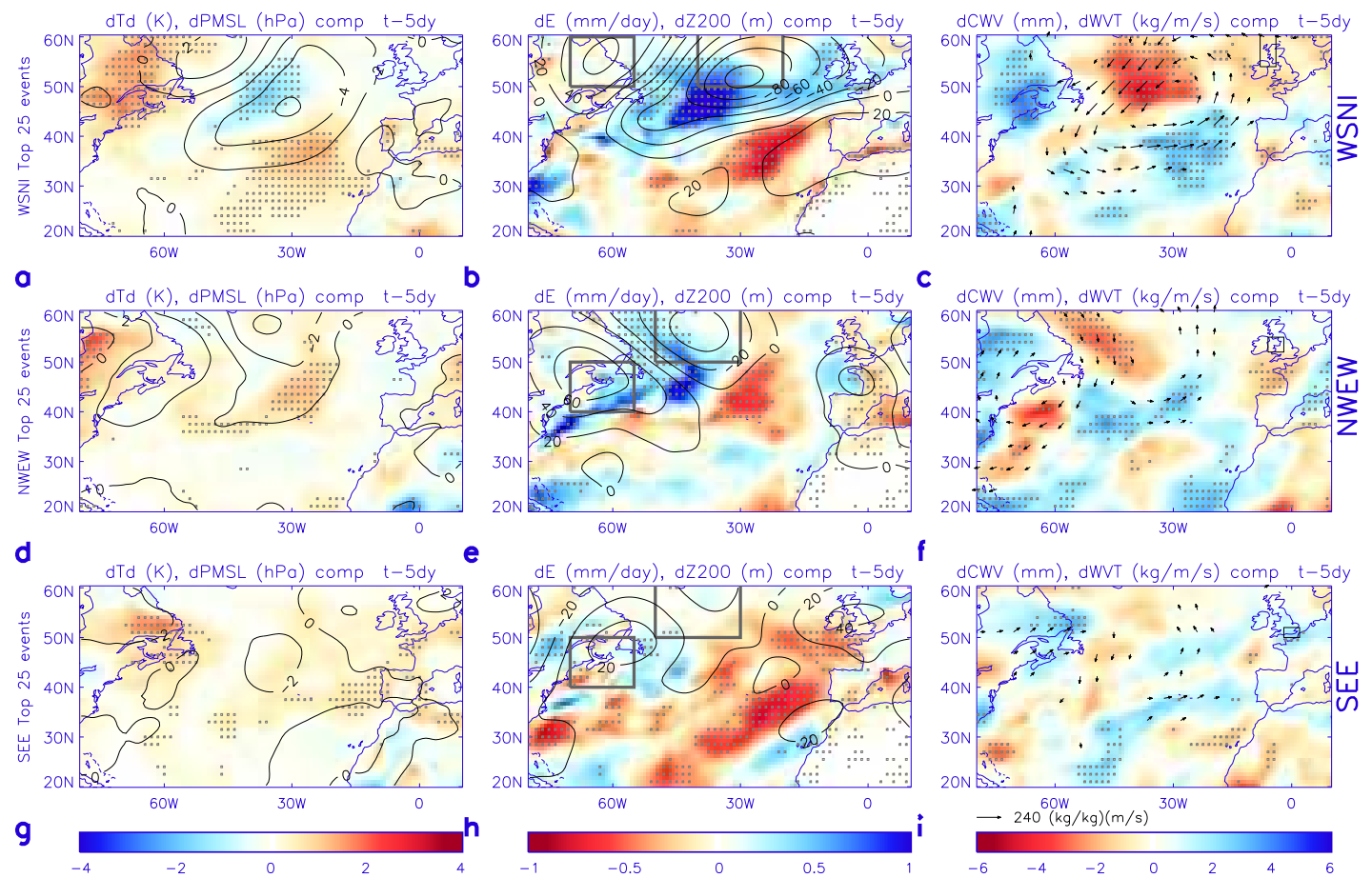

FIG. 12. Large-scale atmospheric precursors to heaviest 25 rainfall events for WSNI (a-c), NWEW (d-f) and SEE (g-i). Boxes (b/e/h) show regions used to construct the geopotential height index, $Z_{I}$.

zonal wind components to diagnose the waviness of the jet stream and its changes over time; here we focus on the geopotential height anomalies linked with the identified heavy rainfall events and as such are not able to make a simple link to the the jet stream structure.

Guided by the results in Fig. 12, to investigate the role of the geopotential height field in intense summer rainfall, an index $\left(Z_{I}\right)$ was constructed to take a ratio of the NFL (60$\left.70^{\circ} \mathrm{W}, 40-50^{\circ} \mathrm{N}\right)$ and $\mathrm{CNA}\left(30-50^{\circ} \mathrm{W}, 50-60^{\circ} \mathrm{N}\right)$ anomalies averaged over the boxes displayed in Fig. 12b,e:

$$
Z_{I}=Z 200_{N F L} / Z 200_{C N A} .
$$

For WSNI we alter the regions due to the shifted anomaly field (NFL: $60-70^{\circ} \mathrm{W}, 50-60^{\circ} \mathrm{N}$; CNA: $20-40^{\circ} \mathrm{W}, 50-60^{\circ} \mathrm{N}$ )

When applying the SEE/NWEW index to the whole UK, 12 of the 25 heaviest 3-hourly rainfall events $(48 \%)$ were preceded by the highest $20 \%$ of $Z_{I}$ anomalies 9-days prior to the events (not shown), consistent with the composites previously constructed. However, only $1.8 \%$ of the highest $20 \%$ of $Z_{I}$ anomalies match any of the heaviest 25 events 9 days later. Although this is more than double the probability due to chance (25 events out of 3312 total days $=0.7 \%$ ) this does not seem to suggest the metric is a useful predictor of heavy rainfall events. Similar results are obtained for the 25 most intense events in the NWEW region (Table 2) while there is less correspondence for the SEE region ( $40 \%$ of the heaviest events were preceded by the highest $20 \%$ of $Z_{I}$ and just $1.5 \%$ of high $Z_{I}$ anomalies matched intense rainfall events 9 days later). For WSNI, a more coherent signal is present and over half of the heaviest 25 rainfall events correspond with the top $20 \%$ of $Z_{I}$ anomalies 5 days prior and 
TABLE 2. Association between above 20th percentile $Z_{I}$ anomalies $\left(Z_{I}^{\prime}\right)$ and the heaviest 50 or 25 3-hourly rainfall events 5 and 9 days later for south east England (SEE) and north west England and Wales (NWEW) and west Scotland and Northern Ireland (WSNI). Columns 3-4 display the percentage of events preceded by elevated $Z_{I}$; columns 5 - 6 show the percentage of elevated $Z_{I}$ days that precede the heaviest rainfall events. Association greater than chance are denoted with bold.

\begin{tabular}{lc|rr|rr|} 
Region & Days prior & \% top 50 & \% top 25 & P(top 50) & P(top 25) \\
SEE & 9 & $\mathbf{2 8 \%}$ & $\mathbf{4 0 \%}$ & $\mathbf{2 . 1 \%}$ & $\mathbf{1 . 5 \%}$ \\
SEE & 5 & $18 \%$ & $\mathbf{3 2 \%}$ & $1.4 \%$ & $\mathbf{1 . 2 \%}$ \\
\hline NWEW & 9 & $\mathbf{3 0 \%}$ & $\mathbf{4 8 \%}$ & $\mathbf{2 . 3 \%}$ & $\mathbf{1 . 8 \%}$ \\
NWEW & 5 & $\mathbf{3 6 \%}$ & $\mathbf{3 2 \%}$ & $\mathbf{2 . 7 \%}$ & $\mathbf{1 . 2 \%}$ \\
\hline WSNI & 9 & $\mathbf{3 0 \%}$ & $\mathbf{4 0 \%}$ & $\mathbf{2 . 3 \%}$ & $\mathbf{1 . 5 \%}$ \\
WSNI & 5 & $\mathbf{4 0 \%}$ & $\mathbf{5 2 \%}$ & $\mathbf{3 . 0 \%}$ & $\mathbf{2 . 0 \%}$ \\
\hline Chance & - & $20 \%$ & $20 \%$ & $1.5 \%$ & $0.7 \%$ \\
Maximum & - & $100 \%$ & $100 \%$ & $7 \%$ & $4 \%$
\end{tabular}

$3 \%$ of these elevated $Z_{I}$ values match one of the heaviest 50 rainfall events 5 days later $\mathrm{A}$ more sophisticated statistical assessment, for example using bootstrapping, was not deemed worthwhile given the weak association identified in this case but could be considered if a more robust link was identified in the future. Given the apparent low skill, it was decided not to investigate this further, though a more detailed future assessment could potentially lead to improved physical understanding and predictability of the link between large-scale atmospheric patterns and precipitation extremes.

\section{Conclusions}

Atmospheric precursors to the most intense 3-hourly summer rainfall events observed by gauges across the UK are constructed from the ERA-Interim reanalysis over the period 1979-2014. Work by Champion et al. (2019) is extended to consider all UK regions and additional thermodynamic variables, exploiting an updated quality controlled rainfall dataset and considering the western Europe region at finer scales. Composites of atmospheric precursors are computed for the most extreme 25 and heaviest 200 rainfall events across each of six UK regions assessed.

In the day before the heaviest 200 summer rainfall events, negative anomalies in sea level pressure (around -2 to $-6 h P a$ ) and $200 h P a$ geopotential height (around -60 to $-100 \mathrm{~m}$ ) are identified to the west or south west of the UK. These coincide with above-average moisture, evaporation and dewpoint temperature over north west Europe. These signals emerge 4 days earlier, although the dynamical fields are less coherent for south east England events. Atmospheric precursors are found to be of larger magnitude and more diverse between regions for composites associated with the 25 heaviest rainfall events. They are characterized by a coherent increase in column integrated moisture locally of around 3-4 $\mathrm{mm}$ in 1 day, similar in magnitude but more rapid than for the 200 event composite. Geopotential height 
increases to the east of the UK 4-days prior to the most extreme 25 events for SEE and SWEW with average or below average moisture. This could indicate that drier, anticyclonic conditions, as suggested by weakly positive sea level pressure anomalies, could be necessary to generate the most extreme events. Reduced soil moisture availability arising from dry conditions alters the balance between the surface latent heat flux from evaporation and the sensible heat flux, resulting in warmer air temperatures and inducing modifications in the planetary boundary layer with potential impacts on convection. Interestingly, Blenkinsop et al. (2015) identified anticyclonic synoptic conditions as the only meteorological regime experiencing above-Clausius Clapeyron increases in hourly precipitation intensity with warmer temperatures for the UK.

The heaviest 25 sub-daily rainfall events affecting 3 regions of the UK (WSNI, NWEW, SEE) are associated with coherent atmospheric circulation patterns that emerge over the north Atlantic 5-days earlier. A tripole geopotential anomaly pattern across the north Atlantic is characterised by positive geopotential height anomalies over Newfoundland and to a lesser extent near to the UK with negative anomalies to the south of Greenland; these are only weakly associated with an increased chance of the heaviest rainfall events 5-days later. However, a strongly negative geopotantial height and sea level pressure anomaly are evident 5 days prior to the heaviest 25 events affecting west Scotland and Northern Ireland. Positive dewpoint temperature over Newfoundland and increased evaporation over the north Atlantic develop at this time and appear to propagate towards the UK although this is less marked for SEE events.

Heavy summer rainfall events are physically linked with anomalous geopotential height that are symptomatic of a more disturbed, less zonal (west to east) jet stream that favours blocking of westerly flow. This results in enhanced or suppressed thunderstorm activity over Europe depending on the position of the atmospheric blocking pattern (Mohr et al. 2019). Atmospheric blocking can cause heat to build up in regions dominated by high pressure, particularly where soils are dry and solar radiation primarily heats the ground rather than being used in evaporating surface water. Where warm, moist southerly flows are also induced this can supply the energy and moisture required for intense rainfall. Previous work has identified such a response over southern France and northern Italy following upper level disturbances that can often be triggered by remote Rossby waves (Nuissier et al. 2011; Grazzini et al. 2019). Thunderstorm activity, that can occasionally become organised mesoscale convective systems, is often enhanced during hot, moist and unstable southerly airflows, often referred to as Spanish Plumes when they influence the UK (Gray and Marshall 1998).

As the climate warms, heavy rainfall is expected to intensify due to the greater amount of atmospheric moisture driven by the Clausius Clapeyron equation (Allan et al. 2014; Dunn et al. 2017). Changes in the dynamical characteristics of storms strongly modulate this simple expectation (Lenderink and Fowler 2017; Fischer and Knutti 2016) with intensification of individual storm systems due to enhanced latent heat release (Nie et al. 2018). It is less clear how the frequency of meteorological events associated with heavy rainfall will alter as the planet warms since this is dependent upon complex dynamical effects and feedbacks involving land, ocean and ice (e.g. Zappa et al. 2018; Boers et al. 2019; Coumou et al. 2014; Dwyer and O'Gorman 2017). For example, spatial shifts in large-scale circulation patterns will strongly influence the frequency of synoptic conditions that favour extreme precipitation such as more anticyclonic conditions affecting the southern UK (Chan et al. 2016) or the frequency of hot, 
moist Spanish Plume events (Lewis and Gray 2010). A more meandering jet stream in response to human-caused climate change has been proposed (e.g. Mann et al. 2017; Francis and Vavrus 2015) and this could potentially increase the frequency of severe heatwaves as well as intense rainfall events affecting summer months (Kornhuber et al. 2019). However the influence of tropical disturbances on mid-latitude extremes and how this connection evolves is also increasingly being appreciated (Scoccimarro et al. 2018; Boers et al. 2019; Wulff et al. 2017). This underlines the importance of investigating how the atmospheric circulation alters in a warming planet. Yet a pragmatic and physically reasonable view is that while the UK will continue to experience fluctuations in weather patterns, when these conspire to produce heavy rainfall, these events will intensify with the possibility for more severe flooding when they occur. Exploiting information from the atmospheric precursor composites developed in this study can provide contextual information, potentially of benefit in forecasting flash flood situations (Flack et al. 2019). It is also vital that observations are used to understand how rainfall is currently changing and it is imperative that reliability and homogeneity, inevitably impacting interpretation, continues to be improved.

\section{Acknowledgments.}

This work was funded by the Natural Environment Research Council SINATRA project (NE/K00896X/1) and the ERA4CS INDECIS project funded by the European Union Grant 690462). Hayley Fowler is funded by the Wolfson Foundation and the Royal Society as a Royal Society Wolfson Research Merit Award holder (grant WM140025). This work benefited from comments by two reviewers. 


\section{REFERENCES}

Ali, H., H. J. Fowler, and V. Mishra, 2018: Global observational evidence of strong linkage between dew point temperature and precipitation extremes. Geophysical Research Letters, doi:10.1029/2018GL080557.

Allan, R., C. Liu, M. Zahn, D. Lavers, E. Koukouvagias, and A. Bodas-Salcedo, 2014: Physically Consistent Responses of the Global Atmospheric Hydrological Cycle in Models and Observations. Surveys in Geophysics, 35, 533-552, doi:10.1007/s10712-012-9213-z.

Allan, R. P., D. A. Lavers, and A. J. Champion, 2015: Diagnosing links between atmospheric moisture and extreme daily precipitation over the UK. International Journal of Climatology, 36 (9), 3191-3206, doi:10.1002/joc.4547.

Bao, J., S. C. Sherwood, L. V. Alexander, and J. P. Evans, 2017: Future increases in extreme precipitation exceed observed scaling rates. Nature Climate Change, 7 (2), 128-132,

Blenkinsop, S., S. C. Chan, E. J. Kendon, N. M. Roberts, and H. J. Fowler, 2015: Temperature influence on intense UK hourly precipitation and dependency on large-scale circulation. Environ. Res. Lett., 10, doi:10.1088/1748-9326/10/5/054021.

Blenkinsop, S., E. Lewis, S. C. Chan, and H. J. Fowler, 2016: Quality-control of an hourly rainfall dataset and climatology of extremes for the UK. International Journal of Climatology, 37 (2), 722-740, doi:10.1002/joc.4735.

Boers, N., B. Goswami, A. Rheinwalt, B. Bookhagen, B. Hoskins, and J. Kurths, 2019: Complex networks reveal global pattern of extreme-rainfall teleconnections. Nature, 1 ,

Carlson, T. N. and F. H. Ludlam, 1968: Conditions for the occurrence of severe local storms. Tellus, 20, 203-226, doi:10.1111/j.2153-3490.1968.tb00364.x.

Champion, A. J., R. P. Allan, and D. A. Lavers, 2015: Atmospheric rivers do not explain UK summer extreme rainfall. Journal of Geophysical Research: Atmospheres, 120 (14), 6731-6741, doi:10.1002/2014jd022863.

Champion, A. J., S. Blenkinsop, X.-F. Li, and H. J. Fowler, 2019: Synoptic-scale precursors of extreme u.k. summer 3-hourly rainfall. Journal of Geophysical Research: Atmospheres, 24, 4477-4489, doi:10.1029/2018jd029664.

Chan, S. C., E. J. Kendon, N. M. Roberts, H. J. Fowler, and S. Blenkinsop, 2016: The characteristics of summer sub-hourly rainfall over the southern UK in a high-resolution convective permitting model. Environmental Research Letters, 11 (9), 94024 ,

Coumou, D., V. Petoukhov, S. Rahmstorf, S. Petri, and H. J. Schellnhuber, 2014: Quasiresonant circulation regimes and hemispheric synchronization of extreme weather in boreal summer. Proceedings of the National Academy of Sciences of the United States of America, 111 (34), $12331-6$, 
Dacre, H. F., P. A. Clark, O. Martinez-Alvarado, M. A. Stringer, and D. A. Lavers, 2014: How do atmospheric rivers form? Bull. Amer. Meteor. Soc., in press, doi: 10.1175/bams-d-14-00031.1.

Dacre, H. F., O. Martínez-Alvarado, and C. O. Mbengue, 2019: Linking atmospheric rivers and warm conveyor belt airflows. Journal of Hydrometeorology, JHM-D-18-0175.1,

Darwish, M. M., H. J. Fowler, S. Blenkinsop, and M. R. Tye, 2018: A regional frequency analysis of UK sub-daily extreme precipitation and assessment of their seasonality. International Journal of Climatology, 38 (13), 4758-4776, doi:10.1002/joc.5694.

Dee, D. P., et al., 2011: The ERA-Interim reanalysis: configuration and performance of the data assimilation system. Quart. J. Roy. Meteorol. Soc., 137, 553-597, doi:10.1002/qj.828.

Dettinger, M. D., F. M. Ralph, T. Das, P. J. Neiman, and D. R. Cayan, 2011: Atmospheric Rivers, Floods and the Water Resources of California. Water, 3, 445-478, doi:10.3390/ w3020445.

Dunn, R. J. H., K. M. Willett, A. Ciavarella, and P. A. Stott, 2017: Comparison of land surface humidity between observations and CMIP5 models. Earth System Dynamics, 8 (3), 719-747,

Dwyer, J. G. and P. A. O'Gorman, 2017: Changing duration and spatial extent of midlatitude precipitation extremes across different climates. Geophysical Research Letters, 44 (11), $5863-5871$,

Fischer, E. M. and R. Knutti, 2016: Observed heavy precipitation increase confirms theory and early models. Nature Climate Change, 6 (11), 986-991,

Flack, D., et al., 2019: Recommendations for improving integration in national end-toend flood forecasting systems: An overview of the FFIR (flooding from intense rainfall) programme. Water, 11 (4), 725, doi:10.3390/w11040725.

Francis, J. A. and S. J. Vavrus, 2015: Evidence for a wavier jet stream in response to rapid arctic warming. Environmental Research Letters, 10 (1), 014 005, doi:10.1088/1748-9326/ 10/1/014005.

Gimeno, L., R. Nieto, M. Vazquez, and D. A. Lavers, 2014: Atmospheric rivers: a minireview. Frontiers in Earth Science, 2, doi:10.3389/feart.2014.00002.

Golding, B., P. Clark, and B. May, 2005: The boscastle flood: Meteorological analysis of the conditions leading to flooding on 16 august 2004. Weather, 60, 230-235, doi:10.1256/ wea.71.05.

Gray, M. E. B. and C. Marshall, 1998: Mesoscale convective systems over the UK, 1981-97. Weather, 53 (11), 388-396, 
Grazzini, F., G. C. Craig, C. Keil, G. Antolini, and V. Pavan, 2019: Extreme precipitation events over northern italy. part i: A systematic classification with machinelearning techniques. Quarterly Journal of the Royal Meteorological Society, in press, doi:10.1002/qj.3635.

Guerreiro, S. B., H. J. Fowler, R. Barbero, S. Westra, G. Lenderink, S. Blenkinsop, E. Lewis, and X.-F. Li, 2018: Detection of continental-scale intensification of hourly rainfall extremes. Nature Climate Change, 8 (9), 803-807,

Hapuarachchi, H. A. P., Q. J. Wang, and T. C. Pagano, 2011: A review of advances in flash flood forecasting. Hydrological Processes, 25 (18), 2771-2784, doi:10.1002/hyp.8040.

Institute of Hydrology, 1996: Hydrological data United Kingdom 1995 Yearbook: an account of rainfall, river flows, groundwater levels and river water quality January to December 1995, Hydrological data UK, Vol. 1995.

Jones, M. R., S. Blenkinsop, H. J. Fowler, and C. G. Kilsby, 2013: Objective classification of extreme rainfall regions for the UK and updated estimates of trends in regional extreme rainfall. International Journal of Climatology, 34 (3), 751-765, doi:10.1002/joc.3720.

Kendon, E. J., N. M. Roberts, H. J. Fowler, M. J. Roberts, S. C. Chan, and C. A. Senior, 2014: Heavier summer downpours with climate change revealed by weather forecast resolution model. Nature Climate Change, 4 (7), 570-576,

Kornhuber, K., S. Osprey, D. Coumou, S. Petri, V. Petoukhov, S. Rahmstorf, and L. Gray, 2019: Extreme weather events in early summer 2018 connected by a recurrent hemispheric wave-7 pattern. Environmental Research Letters, 14 (5), 054002 ,

Lavers, D. A., R. P. Allan, E. F. Wood, G. Villarini, D. J. Brayshaw, and A. J. Wade, 2011: Winter floods in Britain are connected to atmospheric rivers. Geophysical Research Letters, 38, L23803, doi:10.1029/2011GL049783.

Lavers, D. A., D. M. Hannah, and C. Bradley, 2015: Connecting large-scale atmospheric circulation, river flow and groundwater levels in a chalk catchment in southern england. Journal of Hydrology, 523, 179-189, doi:10.1016/j.jhydrol.2015.01.060.

Lavers, D. A., F. Pappenberger, D. S. Richardson, and E. Zsoter, 2016: ECMWF extreme forecast index for water vapor transport: A forecast tool for atmospheric rivers and extreme precipitation. Geophysical Research Letters, 43 (22), 11,852-11,858, doi: 10.1002/2016gl071320.

Lenderink, G. and H. J. Fowler, 2017: Understanding rainfall extremes. Nature Climate Change, 7 (6), 391-393, doi:10.1038/nclimate3305.

Lenderink, G. and E. van Meijgaard, 2010: Linking increases in hourly precipitation extremes to atmospheric temperature and moisture changes. Environ. Res. Lett., 5, 025208, doi: 10.1088/1748-9326/5/2/025208. 
Lewis, E., et al., 2018: A rule based quality control method for hourly rainfall data and a $1 \mathrm{~km}$ resolution gridded hourly rainfall dataset for great britain: CEH-GEAR1hr. Journal of Hydrology, 564, 930-943, doi:10.1016/j.jhydrol.2018.07.034.

Lewis, M. W. and S. L. Gray, 2010: Categorisation of synoptic environments associated with mesoscale convective systems over the UK. Atmospheric Research, 97, 194-213, doi: 10.1016/j.atmosres.2010.04.001.

Mann, M. E., S. Rahmstorf, K. Kornhuber, B. A. Steinman, S. K. Miller, and D. Coumou, 2017: Influence of Anthropogenic Climate Change on Planetary Wave Resonance and Extreme Weather Events. Scientific Reports, 7, 45 242,

McGinnigle, J. B., 2002: The 1952 Lynmouth floods revisited. Weather, 57, 235-242, doi: $10.1256 / 004316502760195894$.

Mohr, S., J. Wandel, S. Lenggenhager, and O. Martius, 2019: Relationship between atmospheric blocking and warm season thunderstorms over western and central europe. Quarterly Journal of the Royal Meteorological Society,

Nie, J., A. H. Sobel, D. A. Shaevitz, and S. Wang, 2018: Dynamic amplification of extreme precipitation sensitivity. Proceedings of the National Academy of Sciences, 115 (38), 201800357

Nuissier, O., B. Joly, A. Joly, V. Ducrocq, and P. Arbogast, 2011: A statistical downscaling to identify the large-scale circulation patterns associated with heavy precipitation events over southern france. Quarterly Journal of the Royal Meteorological Society, 137 (660), 1812-1827, doi:10.1002/qj.866.

O'Gorman, P. A., 2015: Precipitation Extremes Under Climate Change. Current Climate Change Reports, 1 (2), 49-59, , 1503.07557v1.

Pendergrass, A. G., 2018: What precipitation is extreme? Science, 360 (6393), 1072-1073,

Pendergrass, A. G., K. A. Reed, and B. Medeiros, 2016: The link between extreme precipitation and convective organization in a warming climate: Global radiative-convective equilibrium simulations. Geophysical Research Letters, 43 (21), 11,445-11,452,

Pfahl, S., P. A. O'Gorman, E. M. Fischer, P. A. O'Gorman, E. M. Fischer, P. A. O'Gorman, and E. M. Fischer, 2017: Understanding the regional pattern of projected future changes in extreme precipitation. Nature Climate Change, 7 (6), 423-427,

Scoccimarro, E., S. Gualdi, and S. Krichak, 2018: Extreme precipitation events over northwestern Europe: getting water from the tropics. Annals of Geophysics, 61 (Vol 61 (2018)),

Smith, K. and R. Ward, 1998: Floods: Physical Processes and Human Impacts. Wiley.

Stephens, E., J. J. Day, F. Pappenberger, and H. Cloke, 2015: Precipitation and floodiness. Geophysical Research Letters, 42 (23), 10316-10323, 
Wasko, C. and A. Sharma, 2017: Global assessment of flood and storm extremes with increased temperatures. Scientific Reports, 7 (1), 7945,

Wulff, C. O., R. J. Greatbatch, D. I. V. Domeisen, G. Gollan, and F. Hansen, 2017: Tropical forcing of the summer east atlantic pattern. Geophysical Research Letters, 44 (21), 11,16611,173, doi:10.1002/2017GL075493.

Zappa, G., F. Pithan, and T. G. Shepherd, 2018: Multimodel Evidence for an Atmospheric Circulation Response to Arctic Sea Ice Loss in the CMIP5 Future Projections. Geophysical Research Letters, 45 (2), 1011-1019, 